\title{
Inbreeding, Genetic Variation, and Invasiveness: The Strange Case of Bromus tectorum
}

\section{By Susan E. Meyer and Elizabeth A. Leger}

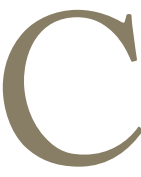

heatgrass (Bromus tectorum, downy brome) is arguably the most common plant in the western United States, dominating literally millions of acres of degraded rangeland; yet it is a relative newcomer, having arrived on the scene only a little over a century ago. It first entered the West as an unknown but probably small number of seeds in contaminated grain or packing material, a few years before the turn of the twentieth century. How did it progress so rapidly from these humble beginnings to become a scourge over such a vast area? Is it still in the process of expansion? The story of how this seemingly innocuous plant has taken over huge areas of western rangelands has engaged the attention of some of our best scientific detectives, and the tale is still not completely told. Unraveling the mystery has required tools from many disciplines, and as new tools are developed and applied, the picture continues to become clearer. Our chapter of the story tells how the tools of population genetics have shed light on the causes of the cheatgrass population explosion.

Land managers who must deal with invasive exotic plants such as cheatgrass rarely consider that the great majority of plants that are introduced fail to establish. Why is successful establishment the exception? Initial success is strongly dependent upon a favorable combination of environmental conditions at the invasion site and properties of the arriving seeds. The newly introduced plants must, just by chance, be preadapted to survive and reproduce under conditions at the site. Most often they are not, and the invasion fails to occur. Traits that determine whether a plant lives or dies under given circumstances are usually under some form of genetic control and may vary among individuals within a population. This makes the topic of ecological genetics central to the question of how exotic plant species establish and become invasive.

Except in the case of escaped ornamentals or crops, the initial genetic makeup of a founder population is determined largely by random processes. In accidental introductions, the amount of genetic variation in the introduced population is often much reduced compared to genetic variation in the source population, because of the relatively small number of individuals that succeed in migrating. ${ }^{1}$ This reduction of the genetic potential of a species during migration is called a genetic bottleneck or, more specifically, a founder effect.

The genetic makeup of the founding population determines whether, and how far, a successfully established species can spread. One possibility is that at least some members of the founder population are broadly adapted, and that these can invade new environments without any genetic modification. Adaptive phenotypic plasticity, or the ability to modify the expression of a trait in a way that increases fitness across variable environments, is under genetic control and can play an important role in invasions. ${ }^{2}$ A genotype with this adaptive phenotypic plasticity in key traits has been termed a "general-purpose" genotype.

Another possibility is that evolutionary change is required before a population can become extremely invasive, or can become invasive in a new type of habitat. ${ }^{4}$ This can occur in two ways. The first way is through natural selection acting upon the array of genetic variation already present in the founding population, increasing the frequency of the most invasive, best-adapted genotypes in the novel environment. The second way is via natural selection operating on novel genetic variation that has arisen locally, through mutation or through recombination, often between previously isolated genotypes. ${ }^{5}$ Though the mechanisms that generate the variation are different, the result of natural selection is an increase in fitness of the invasive species, which can translate into increased population densities or increased range sizes.

Whether an invasive species spreads by possessing general-purpose genotypes or by evolving adaptations to particular environments is reflected in patterns of population differentiation across a landscape. If a species invades a wide area via phenotypic plasticity, there will likely be little differentiation in adaptive traits among populations, and the random process of genetic drift is more likely to determine how genetic variation is distributed, rather than natural selection. If, on the other hand, natural selection has been 
important in the spread of an invader, it will leave a signature pattern of population differentiation on the landscape, such that plants collected from particular environments will perform better there than in other environments, a phenomenon known as local adaptation. Because there is a limit to the extent that phenotypic plasticity can permit colonization of new environments, the ability to evolve locally adapted races greatly increases the invasion potential of a species. There is evidence that evolutionary change has facilitated invasion into new habitats for many invasive species. $^{6}$

Breeding system is an additional factor that is very important in determining the genetic structure of a founder population and that may affect potential invasiveness. Outcrossing species generate novel genotypic variation much more readily than inbreeding species, whereas inbreeders are more able to preserve intact the suites of adaptive traits that may confer high fitness in a particular environment.

\section{Why Is Cheatgrass So Successful?}

Some of the attributes of a highly successful invader can be characterized at the species level, whereas others require a detailed study of population genetic structure. What are some key attributes of cheatgrass as a species, and would they lead us to expect it to be so massively successful in the Great Basin? Some of the likely answers to this question are based primarily on ecological characteristics that are shared by a majority of cheatgrass plants.

Cheatgrass is an annual plant. In most models of ecological succession, annual plants dominate only on short timescales after disturbance, or they may codominate with shrubs in very arid environments. How can an annual plant like cheatgrass displace native perennial vegetation and bring succession to a standstill in less harsh, semiarid environments? Cheatgrass is able to exploit disturbance at multiple spatial scales to become established even in apparently intact native vegetation. If massive disturbance takes place, it can rapidly expand to fill the space available. Very widespread unsound livestock grazing practices in the late nineteenth century created such a massive disturbance opportunity in the Intermountain West. Cheatgrass, aided in its dispersal by the same livestock that created disturbance, quickly moved in. Once established, cheatgrass has the ability to perpetuate disturbance because of its high flammability - in effect, it creates the disturbance it needs to perpetuate itself, by greatly increasing the frequency of fire.

Cheatgrass is also a prodigious seed producer. Under favorable conditions, a single plant can produce hundreds of seeds, and each one has a high potential for establishment. Cheatgrass also has high plasticity for traits involving seed production. Even in adversity, a cheatgrass plant usually manages to produce at least one seed, and if times are good, it can respond by producing a truly astonishing number of seeds. As mentioned above, cheatgrass is also extremely good at seed dispersal, over both short and long distances. Its adaptations for dispersal by animals are well known to any hiker who has had to decide whether his or her seed-infested socks were even worth trying to salvage.

Cheatgrass also tends to be highly competitive for belowground resources, with an extensive fine root system that usurps available water and nutrients from the soil. Because it is a winter annual, it does not need to survive the harsh, dry summer, as native perennial seedlings must. It leaves few or no resources behind for native seedlings to utilize late in the season, making summer mortality of perennial seedlings much more likely.

Last, cheatgrass is primarily a self-pollinating species. A selfing breeding system gives cheatgrass an advantage in initial establishment, because it can produce seeds without a partner - in theory, one seed could found a population.

It appears that cheatgrass was poised to be successful from the time it first arrived in the West, with whatever genetic variation it carried, because of the chance conjunction of a species with these particular traits and a newly vulnerable ecosystem. However, there is considerable evidence for adaptive shifts in the genetic makeup of $B$. tectorum after introduction to North America, both when comparing North American populations to possible European ancestors and when looking at patterns of population differentiation in the introduced range.

\section{Where Did Cheatgrass Come From, and Is It Continuing to Adapt to New Habitats?}

One often-asked question is how well cheatgrass can adapt to new environments and thereby expand its dominance into habitats where it has historically been relatively unimportant. Among the most interesting and valuable population genetic studies of cheatgrass are those that address this question by tracing the history of cheatgrass invasion from points of entry into North America, and the western United States in particular. These studies have also asked how area of origin might have influenced invasion potential by influencing the genetic composition of founder populations. Studies using isozyme markers indicate that there were multiple independent introductions of cheatgrass directly into the western United States from different parts of its European range in the late 1800s, and that the molecular genetic signatures of these events have persisted. ${ }^{7}$ Multiple introductions increased the amount of genetic variation available for natural selection to operate upon, making success in a wide range of habitats more likely, as gene flow via seed dispersal increased the amount of genetic variation in many populations. ${ }^{1,7}$ Populations in eastern and central North America appear to have established from separate, earlier introductions along the eastern seaboard, and there has been little apparent gene flow between populations of descendents of these eastern and western introductions. ${ }^{8}$ 
Isozyme data can give clues to the origins of North American populations, but to address whether North American populations have undergone adaptive genetic changes requires common garden or reciprocal transplant studies (Fig. 1). In a common garden study with European, North American, and New Zealand sources, Kinter and Mack ${ }^{9}$ demonstrated that, just by chance, genotypes with growth traits conferring possible high invasion potential were introduced into western North America from eastern Europe, while genotypes with traits conferring lower invasion potential, probably from further west in Europe, were apparently introduced into similar environments in New Zealand but have not become particularly invasive there. Natural selection would operate to increase the abundance of genotypes with high invasion potential, but if these genotypes were never introduced, then such an adaptive shift might not be possible.
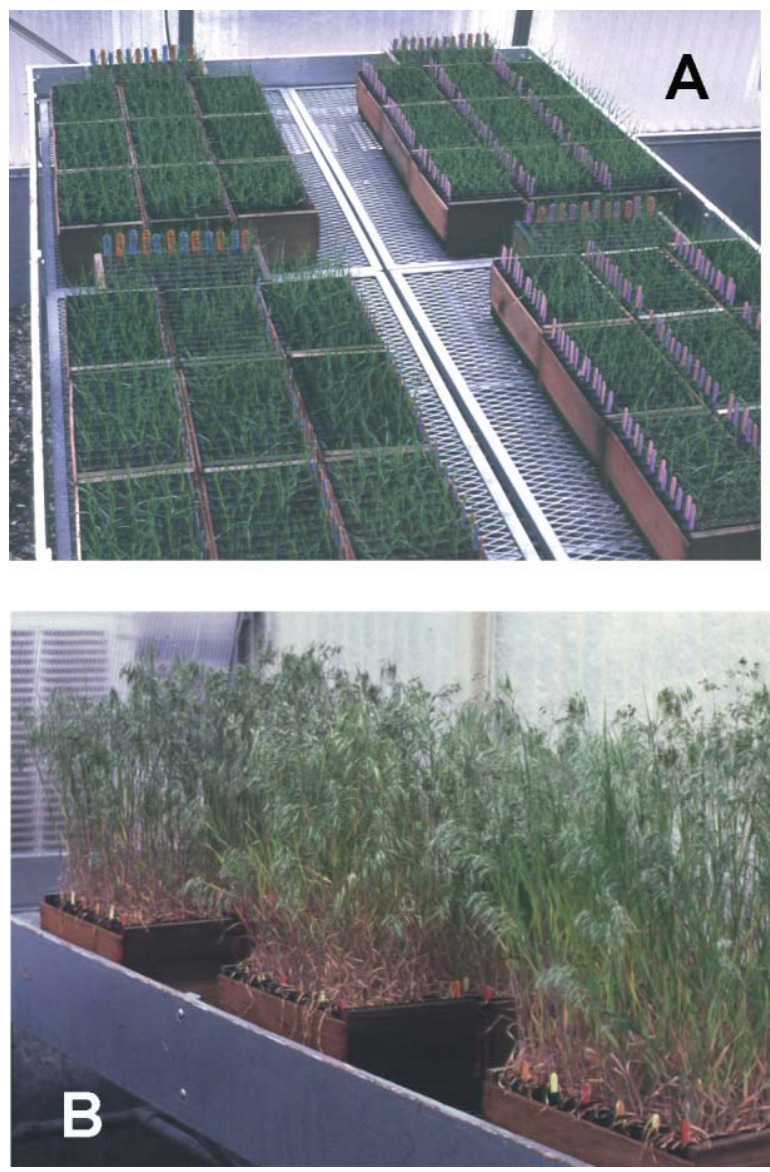

Figure 1. Common environment studies with different genotypes of cheatgrass permit the separation of genetic and environmental effects on phenotype. The experiments pictured here dealt with the resistance of different cheatgrass genotypes to particular virulence races of the pathogen Ustilago bullata, which causes head smut disease and prevents seed set in infected plants (Meyer et al.):12 A, seedlings ready to go into winter chilling to induce flowering; B, flowering plants ready for scoring for levels of smut infection.
As evidence for adaptive shifts in western North America, a reciprocal transplant study in eastern Washington ${ }^{10}$ demonstrated that populations of $B$. tectorum from two extreme environments showed evidence of local adaptation, whereas populations in more typical environments did not. These and other common environment studies demonstrate that not all cheatgrass is created equal, and that there is considerable variation for traits that are likely to control the distribution and abundance of this plant in different environments. Some studies have proposed that phenotypic plasticity is the whole answer to cheatgrass success, but we have uncovered an abundance of adaptively significant variation in different genotypes of this species, involving traits such as regulation of resource allocation, seed germination phenology, seed weight, flowering time, and disease resistance (Fig. 2). ${ }^{11-15}$ This means we need to take a closer look at the relative importance of locally adapted specialist genotypes versus general purpose genotypes in this species.

Evidence to date suggests that cheatgrass is making use of general-purpose genotypes with high phenotypic plasticity as well as evolving locally adapted genotypes in continuing to increase its abundance and the range of habitats it can occupy in western North America. As determined by SSR (microsatellite) genotyping, most populations are apparently dominated by one to a few highly selfing lines. ${ }^{16}$ Several of these lines have suites of traits (adaptive syndromes) that specifically adapt them to extreme environments, particularly at the drier end of the spectrum of habitats that this species can occupy. For example, populations in the northern Mojave Desert are dominated by an SSR genotype that has been found rarely and at low frequency elsewhere (Fig. 3). This genotype possesses extended seed dormancy at summer temperatures and short winter chilling requirements for flowering, traits that clearly preadapt it for life in the warm desert. ${ }^{11,13}$ Similarly, extreme salt desert populations in the Great Basin are usually dominated by one of two inbreeding lines, at least one of which is characterized by high salinity tolerance and the rapid growth necessary to successfully set seed in a rapidly drying saline environment. ${ }^{14,17}$ On the other hand, less extreme habitats frequently support more cheatgrass SSR genotypes, but most often a single population is still dominated by only a handful of genotypes. At least one common SSR genotype abundant in steppe habitats also occurs over a very wide geographic range and across a range of habitats (Fig. 3). It may represent a classic general purpose genotype. ${ }^{16}$ The main lesson of our work with cheatgrass SSR markers is that inbreeding lines with specific SSR fingerprints and associated adaptive syndromes tend to occur in the same habitats over a wide geographic range. It is quite likely, however, that potentially adapted genotypes have not yet dispersed to all possible habitats, meaning that a location not yet seriously invaded may just be awaiting the arrival of a suitably adapted genotype. For example, there is evidence that a presumably highly invasive Intermountain isozyme 

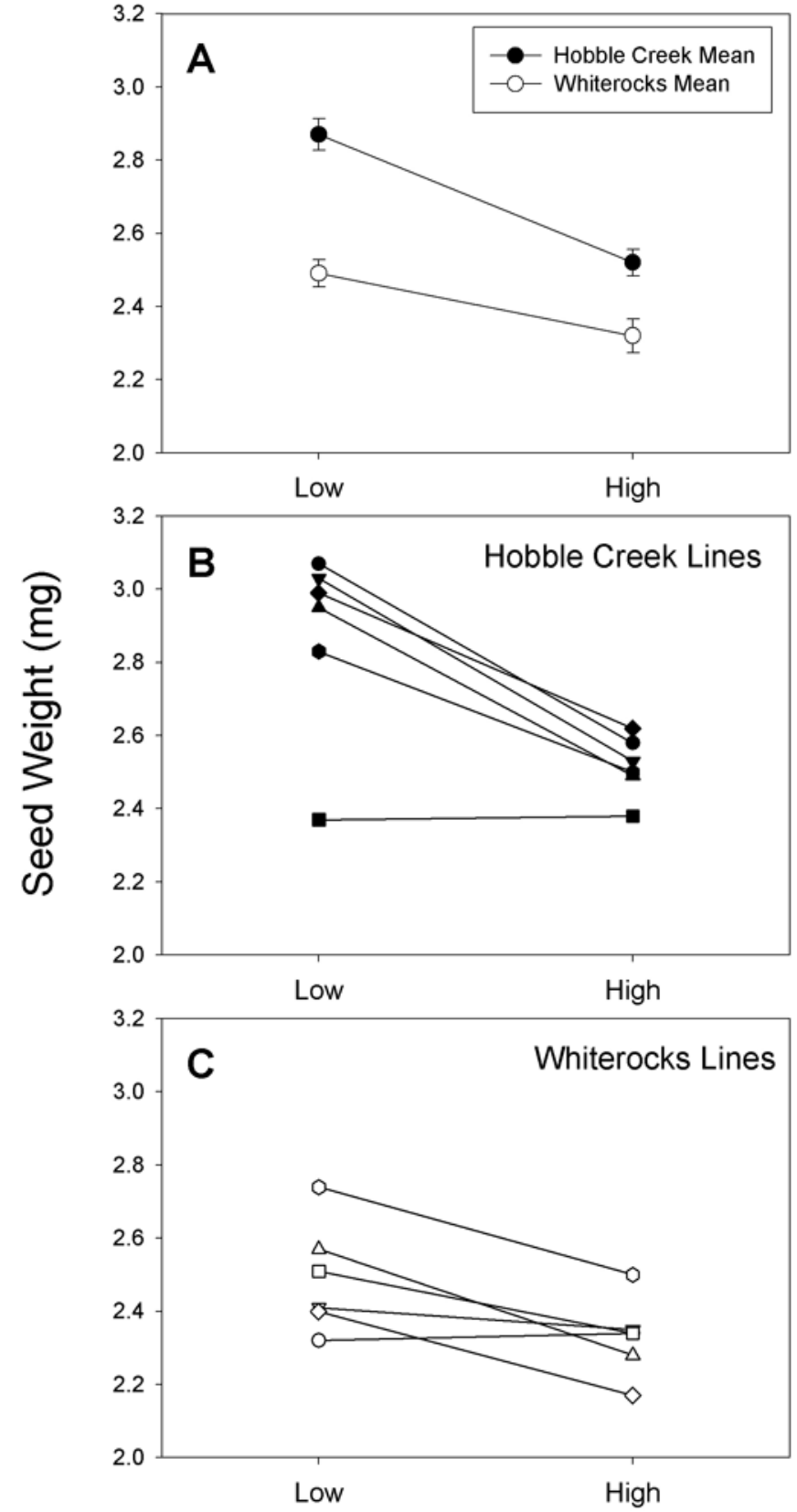

Temperature Treatment

Figure 2. This common garden study examined variation in weight for seeds from two cheatgrass populations produced in greenhouse environments with contrasting temperature regimes (low vs. high temperature) during growth and development (see Meyer et al. ${ }^{12}$ for experimental details). Seed weight means are shown at each temperature for $\mathbf{A}$, each population overall (bars are standard errors); B, six Hobble Creek inbreeding lines; and C, six Whiterocks inbreeding lines. Hobble Creek lines overall had higher mean seed weight than Whiterocks lines and were also more phenotypically plastic in response to temperature (steeper slope). Within populations, lines differed both in mean seed weight and in phenotypic plasticity of the temperature response, with a few lines showing no downward shift in weight at high temperature. This study demonstrates amongand within-population genetic variation both for mean seed weight and for seed weight phenotypic plasticity in response to maturation temperature. This plasticity is adaptive because it enables plants of a given genotype to produce larger seeds when conditions are good (cool) but does not sacrifice seed quality for size under more stressful (warm) conditions.

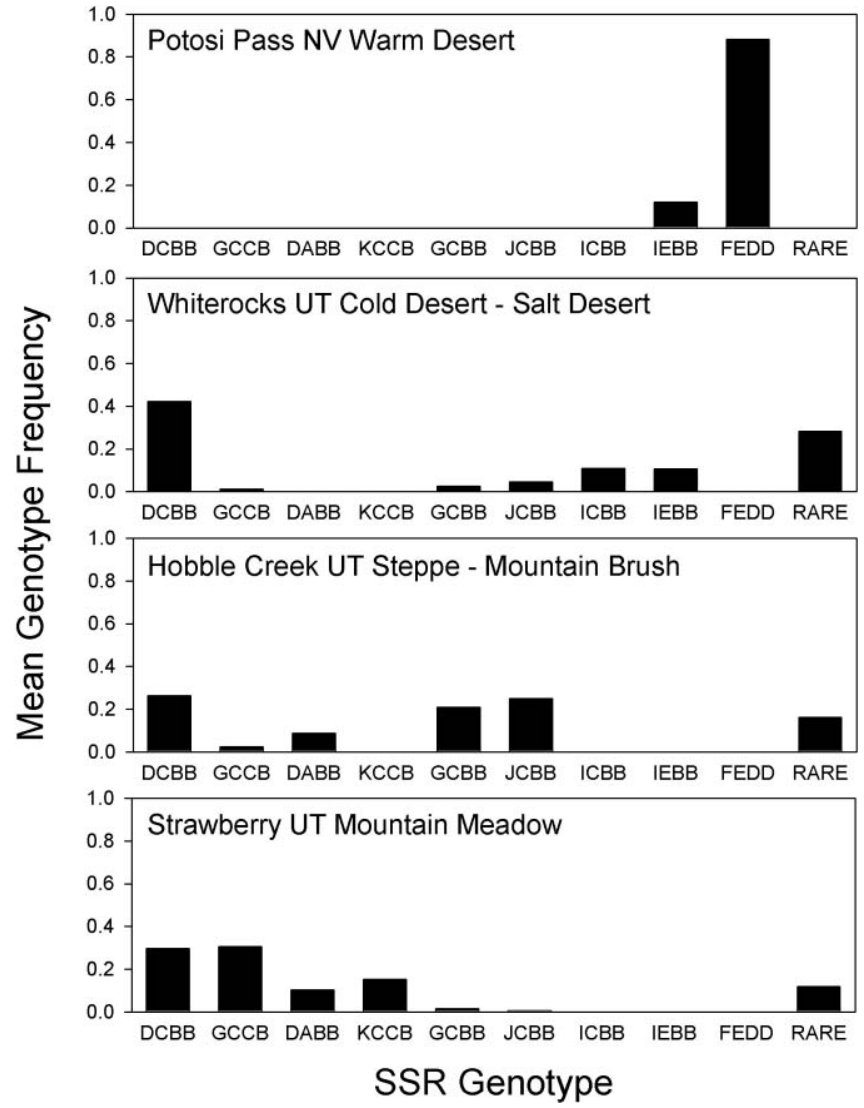

Figure 3. Frequency distribution of nine common (frequency $>0.10$ in at least one population) SSR genotypes in four cheatgrass populations from contrasting habitats in Utah and Nevada (adapted from Ramakrishnan et al.). ${ }^{16}$ Right-hand bar in each graph shows total frequency of rare genotypes (frequency $<0.10$ ) in each population. The genotype DCBB (left-hand bar) was common across cold desert, foothill, and montane populations and is postulated to represent a "general purpose" genotype. Remaining common genotypes clearly sorted into habitats, with FEDD dominating the Mojave Desert population and absent elsewhere, IEBB and ICBB best represented in the cold desert population, GCBB and JCBB best represented in the foothill population, and GCCB, DABB, and KCCB best represented in the montane population. The pattern of specific SSR genotypes sorting into habitats was supported by a wider population survey also included in Ramakrishnan et al. ${ }^{16}$ These patterns have also emerged clearly in a much larger data set representing 96 populations from throughout the Intermountain West (K. R. Merrill, S. E. Meyer, and C. E. Coleman, unpublished data, 2009).

genotype has apparently only recently appeared east of the Rockies, in Laramie, Wyoming. ${ }^{8}$ The arrival of this genotype could potentially be followed by an increase in cheatgrass invasion in a previously minimally invaded area.

Last but not least, we need to consider the role of recombination in the invasion potential of cheatgrass. As mentioned above, B. tectorum is primarily a selfing plant, which can be advantageous when founding new populations from very limited number of seeds. However, without the benefit of the recombination that accompanies outcrossing, the ability to generate novel genotypic variation as a basis for selection is severely hampered. This could be a 
Common Terms Used in Population Genetics Studies

Adaptation: A genetic trait that confers a fitness advantage

Adaptive syndrome: A group of traits that work together to confer a fitness advantage

Allele: One of multiple variants or forms of a gene

Common garden study: Studies where progeny of plants collected from multiple populations are grown in a single environment in order to minimize the effects of nongenetic factors on plant phenotypes

Ecological genetics: The study of genetic variation that affects the outcome of interactions between an organism and its environment

Evolutionary change: Change in allele frequencies within a population via natural selection, genetic drift, mutation, or gene flow

Fitness: Reproductive success, typically measured as number of seeds or offspring per individual

Gene flow: Movement of alleles between populations via seed dispersal or pollen movement

"General-purpose" genotype: A highly phenotypically plastic genotype capable of growing in many different environments via adaptive shifts in traits that increase fitness across a variety of conditions

Genetic bottleneck or founder effect: A genetic bottleneck is loss of genetic diversity after an event that severely reduces population size. A founder effect refers to a particular type of genetic bottleneck that occurs when a new population is started by a small number of individuals.

Genetic drift: Shifts in allele frequencies in a population based on random factors, rather than on natural selection

Genotype: The set of alleles contained within a particular organism; also used to refer to a group of individuals that share specific alleles at a set of genes

Isozyme: Enzymes that differ in form but not function, thus presumed to be invisible to natural selection, used for population genetic studies; also referred to as "allozymes"

Local adaptation: An increase in fitness that results from natural selection in a specific environment

Mutation: A random change in the DNA sequence of a gene

Natural selection: Changes in allele frequencies in a population due to differential survival and reproduction of individuals with particular alleles

Phenotype: The physical or physiological expression of genotype

Phenotypic plasticity: The ability of an organism to modify its phenotype in response to environmental shifts; adaptive phenotypic plasticity refers to such changes that increase fitness within a particular environment
Common Terms (continued)

Population genetics: The study of allele frequency changes in populations

Preadaptation: Possession by a genotype of favorable characteristics for growing in a particular environment, though the characteristics are not the product of natural selection in that specific environment

Reciprocal transplant study: A study to determine the degree of local adaptation in plant populations by planting genotypes from contrasting environments into their own and the contrasting environment and measuring fitness

Recombination: Formation of genotypes different from parental ones via sexual reproduction

SSR (single sequence repeat) marker: Areas of genomic DNA with specific nucleotide repeats, useful for population genetic studies; also referred to as "microsatellites"

disadvantage in invading novel habitats. For lines that are highly specialized for life in a stressful habitat, outcrossing may be harmful, in that it could disrupt existing adaptive syndromes and result in progeny that are less fit than the specialized parent. On the other hand, recombination could result in the generation of novel genotypes with traits necessary for invasion into novel environments. Chance formation of genotypes that would have little likelihood of expanding in frequency in more benign habitats could form the basis of newly adapted cheatgrass populations in marginal habitats.

Whether recombination helps or hinders adaptation in cheatgrass is not yet known, but we do know that some populations, and perhaps some SSR genotypes, seem to be more prone to outcrossing than others. ${ }^{15,17}$ Overall the level of outcrossing in this species has been measured to be much less than $1 \%$, but given the millions of plants per hectare, even this low rate could generate large numbers of recombinant genotypes. A real assessment of outcrossing rates for different genotypes of cheatgrass in different habitats, and the effects of this outcrossing on population dynamics, awaits the development of an even more sensitive molecular marker system. This will be the next chapter in the unfolding cheatgrass ecological genetics story.

\section{Conclusions}

The extreme success of cheatgrass in the Intermountain West probably results at least in part from species attributes such as high seed production, high plasticity, high competitive ability, high dispersal potential, and the ability to promote the disturbance it needs to perpetuate its own dominance. However, it also has a complex population genetic structure, which includes a combination of specialist genotypes, general purpose genotypes, and the progeny of outcrossed individuals with novel evolutionary potential. This undoubtedly contributes substantially to cheatgrass success over a very wide range of habitats. This dangerous 
combination of traits suggests that cheatgrass is not yet finished with its takeover of the West.

\section{References}

1. Dlugosch, K. M., And I. M. Parker. 2008. Founding events in species invasions: genetic variation, adaptive evolution, and the role of multiple introductions. Molecular Ecology 17: 431-449.

2. Richards, C. L., O. Bossdorf, N. Z. Muth, J. Gurevitch, AND M. Pigliucci. 2006. Jack of all trades, master of some? On the role of phenotypic plasticity in plant invasions. Ecology Letters 9:981-993.

3. Baker, H. G. 1965. Characteristics and modes of origin of weeds. In: H. G. Baker and G. L. Stebbins [EDs.]. The genetics of colonizing species: proceedings. New York, NY, USA: Academic Press. p. 147-172.

4. LeE, C. E. 2002. Evolutionary genetics of invasive species. Trends in Ecology and Evolution 17:386-391.

5. Ellstrand, N. C., and K. A. Schierenbeck. 2000. Hybridization as a stimulus for the evolution of invasiveness in plants? Proceedings of the National Academy of Sciences of the United States of America 97:7043-7050.

6. Dietz, H., and P. J. Edwards. 2006. Recognition that causal processes change during plant invasion helps explain conflicts in evidence. Ecology 87:1359-1367.

7. Novak, S. J., AND R. N. Mack. 2001. Tracing plant introduction and spread: genetic evidence from Bromus tectorum (cheatgrass). Bioscience 51:114-122.

8. Schachner, L. J., R. N, Mack, and S. J. Novak. 2008. Bromus tectorum (Poaceae) in midcontinental United States: population genetic analysis of an ongoing invasion. American Journal of Botany 95:1584-1595.

9. Kinter, C. L., And R. N. Мack. 2004. Comparing phenotypes and fitness of native, naturalized, and invasive populations of downy brome (cheatgrass, Bromus tectorum). In: A. L. Hild, N. L. Shaw, S. E. Meyer, D. T. Booth, and E. D. McArthur [comps.]. Proceedings of a Conference on Seed and Soil Dynamics in Shrubland Ecosystems; 12-16 August 2002; Laramie, WY, USA; Proceedings RMRS-P-31. Ogden, UT,
USA: US Forest Service, Rocky Mountain Research Station. p. 18-23.

10. Rice, K. J., And R. N. Mack. 1991. Ecological genetics of Bromus tectorum. 3. The demography of reciprocally sown populations. Oecologia 88:91-101.

11. Meyer, S. E., And P. S. Allen. 1999. Ecological genetics of seed germination regulation in Bromus tectorum L. I. Phenotypic variance among and within populations. Oecologia 120:27-34.

12. Meyer, S. E., D. L. Nelson, and S. Clement. 2001. Evidence for resistance polymorphism in the Bromus tectorumUstilaga bullata pathosystem: implications for biocontrol. Canadian Journal of Plant Pathology 23:19-27.

13. Meyer, S. E., D. L. Nelson, and S. L. Carlson. 2004. Ecological genetics of vernalization response in Bromus tectorum L. Annals of Botany 93:653-663.

14. Scott, J. W., S. E. Meyer, K. R. Merrill, and V. J. Anderson. 2010. Local population differentiation in Bromus tectorum L. in response to habitat-specific selection regimes. Evolutionary Ecology (in press).

15. Leger, E. A., E. Espeland, K. R. Merrill, and S. E. Meyer. 2009. Genetic variation and local adaptation at a cheatgrass (Bromus tectorum) invasion edge in western Nevada. Molecular Ecology 18:4366-4379.

16. Ramakrishnan, A. P., S. E. Meyer, D. J. Fairbanks, and C. E. Coleman. 2006. Ecological significance of microsatellite variation in western North American populations of Bromus tectorum. Plant Species Biology 21:61-73.

17. Ashley, M. C., and W. S. Longland. 2007. Microsatellite evidence of facultative outcrossing in cheatgrass (Bromus tectorum): implications for the evolution of invasiveness. Plant Species Biology 22:197-204.

Authors are Research Ecologist, US Forest Service, Rocky Mountain Research Station, Shrub Sciences Laboratory, $735 \mathrm{~N}$ 500 East, Provo, UT 84606 USA, smeyer@fs.fed.us (Meyer); and Assistant Professor, Department of Natural Resources and Environmental Science, University of Nevada, Reno, $1664 \mathrm{~N}$ Virginia St, MS 370, Reno, NV 89557, USA (Leger). 